\title{
Commentary
}

\section{Positive interactions in ecology: filling the fundamental niche}

\author{
Mariano A. Rodriguez-Cabal ${ }^{1}$, M. Noelia Barrios-Garcia, and Martin A. Nuñez \\ Mariano A. Rodriguez-Cabal (rcabal@utk.edu), Department of Ecology and Evolutionary Biology, University of \\ Tennessee, Knoxville, TN, USA 37996 \\ M. Noelia Barrios-Garcia (mbarrios@utk.edu), Department of Ecology and Evolutionary Biology, University of \\ Tennessee, Knoxville, TN, USA 37996 \\ Martin A. Nuñez (nunezm@gmail.com), Department of Ecology and Evolutionary Biology, University of Tennessee, \\ Knoxville, TN, USA 37996 \\ ${ }^{1}$ corresponding author
}

\begin{abstract}
The role of negative interactions in shaping ecological communities and the realized niches of species has been a focus of considerable research for at least decades. Traditionally, the discrepancy between the size of the fundamental and realized niches of a species was attributed to the effect of negative interactions, such that the realized niche is always smaller than the fundamental niche. However, in the last decade, a series of studies have highlighted the important role that positive interactions played in shaping the structure of communities. This renewed interest in positive interactions has led to a reconsideration of the niche concept. Specifically, some investigators have suggested that positive interactions can lead the realized niche of a species to be larger than its fundamental niche. Here, we show that, although positive interactions can counteract the effects of negative interactions and possibly modify the realized niche of a species, the realized niche of a species can never be larger than the fundamental niche.
\end{abstract}

Key words: facilitation, fundamental niche, Hutchinson, positive interactions, realized niche

\section{Introduction}

The niche concept is an integral part of ecology, both currently and historically (Hardin 1960, Leibold 1995,
Hubbell 2001, Chase and Leibold 2003, Levine and HilleRisLambers 2009, Pullian 2000, Vergnon et al. 2009, Chase and Myers 2011, Kylafis and Loreau 2011). However, the niche concept has been defined in several different ways, and remains one of the most confusing topics in ecology. Grinnell (1917) defined the niche as the place that a species occupies in the environment. Elton's (1927) view of the niche differed from Grinnell's in that it focused on the functional role a species plays and its impact on the community. Both Grinnell's and Elton's niche definitions attributed niches to environments. Hutchinson (1957) instead attributed the niche to the species, and this definition is perhaps the most frequently used. Hutchinson (1957) defined the fundamental niche $(N)$ as the sum of all $X_{n}$ variables, both physical and biological, required for a species (S) to persist. Moreover Hutchinson (1957) applied the Volterra-Gause principle (Gause 1934) to described the realized niche $\left(\mathrm{N}_{1}^{\prime}\right)$ of a species $\left(\mathrm{S}_{1}\right)$ in the presence of another species $\left(\mathrm{S}_{2}\right)$ as the proportion of the fundamental niche of $\mathrm{S}_{1}$ that is outside of the fundamental niche of $S_{2}\left(N_{1}-N_{2}\right)$, plus the intersection of both fundamental niches $\left(\mathrm{N}_{1} \cdot \mathrm{N}_{2}\right)$ in which the birth rate of $S_{1}$ is equal to or greater than its death rate. Thus, ecologists generally credit the discrepancy between the size of the fundamental and the realized niches of a species to negative interactions such as competition (Figure1a). 
a)

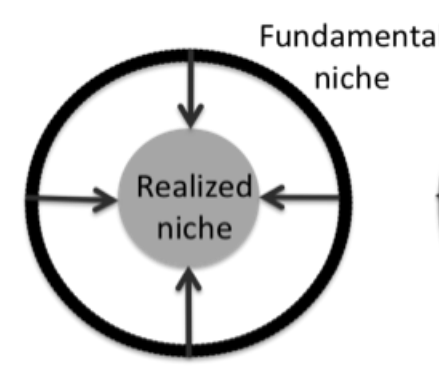

b) Bruno et al. 2003

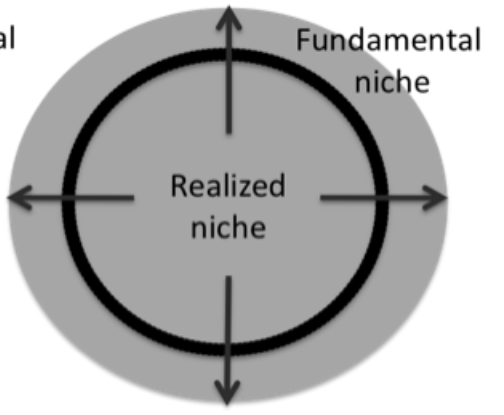

c)

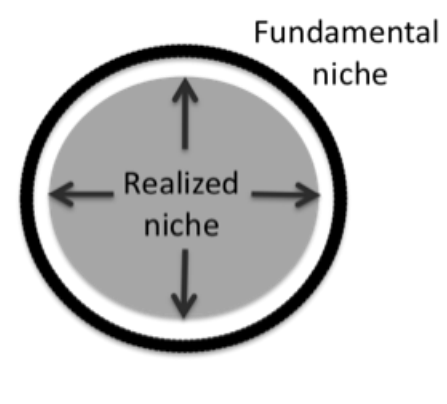

Figure 1. Three different niche concepts. a) Hutchinson (1957)'s niche concept, the realized niche (grey circle) is the part of fundamental niche (black line) occupied by a species after accounting for negative interspecific interactions (such as predation, competition and parasitism). b) Bruno et al. (2003) niche concept, when facilitation is considered the realized niche (grey circle) can be larger than the fundamental niche (black line). c) Our hypothesis, that facilitation can mitigate the effects of negative interactions and expand the realized niche (grey circle) which is larger in (c) than in (a) but cannot overcome the fundamental niche (black line).

Whereas the role of negative interactions in shaping natural communities has been the focus of ecological research (and heated debate) for decades (e.g. MacArthur 1958, Paine 1966, Janzen 1970, Tilman 1994), positive interactions were largely ignored until recently (e.g. Stachowicz 2001, Callaway et al. 2002, Bronstein et al. 2003, Bruno et al. 2003, Brooker et al. 2008, Van der Putten 2009). A positive interaction occurs when the presence of one species enhances the growth, survival, or reproduction of the interacting partner or neighbor but neither is negatively affected. Consequently, positive interactions may have a strong influence on the spatial distribution of associated species over ecological (Choler et al. 2001) or evolutionary time scales (Valiente-Banuet et al. 2006). A series of studies on plant communities (e.g., Callaway 2007 and references therein) have highlighted the ubiquity of facilitation and its importance in shaping the structure of plant communities.

Bruno et al. (2003) further suggested that the inclusion of facilitation into niche theory leads to the paradox that the spatial extent of the realized niche can exceed the spatial range predicted by the fundamental niche (Figure 1b). Bruno et al. (2003) argue that by increasing the spatial extent of the distribution of a species, that species is thereby exposed to new conditions, and as such, the size of its realized niche has exceeded the size of its fundamental niche. But some empirical studies, such as Warren et al.'s (2010) work on ant-seed dispersal mutualisms clearly demonstrated that facilitation failed to expand the size of the realized niche of myrmecochorous plant species over the fundamental niche of that same species. Here, we suggest that the size of the realized niche cannot exceed the size of the fundamental niche, even though the spatial extent of the realized niche might indeed increase with positive interactions (Figure 1c).

To support this contention, we offer five examples from the invasion biology literature. Invasive exotic species often become integrated into the recipient communities, disrupt the function of those communities, and potentially create a new set of associations with native species (Richardson et al. 2000, Pearson and Callaway 2003, Aizen et al. 2008). However, in a small number of cases, exotic species have facilitated a few native species via direct and indirect mechanisms (Vitousek et al. 1987, Vitousek and Walker 1989, Riera et al. 2002, Wonham et al. 2005, Pearson 2009). The consequences of facilitation by exotic invasive species include, for example, geographical range expansion, changes in abiotic conditions, or changes in food availability (Rodriguez 2006). In the following examples, we show how the realized niche of native species has increased in the presence of exotic species without affecting the size of fundamental niche of the natives.

\section{Lessons from exotic species}

In mutualistic interactions, such as plant-pollinator and plant-seed disperser interactions, the spatial distribution of one species is often limited by the extent of the interacting partner's distribution. For example, the introduction of exotic carnivore species in the Balearic Archipelago resulted in an increase in the distribution of the native shrub Cneorum tricoccon (Riera et al. 2002). Seeds of these native shrubs were dispersed by native lizards in the genus Podarcis, which have become extinct following the introduction of several exotic 
carnivores. One of these exotic carnivore species, the pine marten (Martes martes), is also an important seed disperser. Records show that while native seed-dispersing lizards on the island of Majorca are restricted to low elevations (i.e., <500 m.a.s.1.), the current distribution of the plant extends up to 1000 m.a.s.l. Evidence based on seed dispersal experiments suggests that the exotic marten is responsible for the geographic range expansion of the native plant to high elevations. Thus, although the extent of the realized niche (i.e., increased elevation range) of these plants has increased following the introduction of the exotic species, the broad-scale geographic distribution of this plant group suggests that it is pre-adapted to these "new" abiotic conditions, which are included in its fundamental niche. Similarly, in a study of the seed dispersal interaction of the bloodroot (Sanguinaria canadensis) by the red imported fire ant (hereafter RIFA; Solenopsis invicta Buren), Ness et al. (2004) found that RIFA affected seed destination by increasing dispersal toward forest edge ecotones, where native ant species rarely dispersed seeds. Thus, facilitative interactions between the exotic ant and the native plant led to a local increase in the spatial extent of blood-root (e.g., number of patches occupied). An additional study with blood-root showed that it can tolerate the physical conditions typical of forest gaps and can grow vigorously in light-rich habitats (Marino et al. 1997). Therefore, while blood-root might be filling a greater portion of its fundamental niche than before the introduction of RIFA, the range of the conditions that predicted its fundamental niche has not changed.

The spread of exotic species often results in physical alteration of existing habitats, which can include changes in abiotic conditions by creating new microhabitats. Such is the case of Ficopomatus enigmaticus, which is an invasive reef-building polychaete that creates new habitat for a number of native marine species. Schwindt and Iribarne (2000) found that many native species of crabs, amphipods, and gastropods were more abundant beneath this reef-building polychaete than in non-invaded sites, due to the introduction of novel physical structures that change the abiotic conditions and provide refuge against predators. Similarly, the Asian hornsnail (Batillaria attramentaria) - exotic to the Northwest Pacific coast of the United States-facilitates the establishment of native species, including two native hermit crabs (Pagurus hirsutiusculus and P. granosimanus), and exotic species (Wonham 2005). These species used the shell of the Asian hornsnail as substrate and refuge. However, these are examples of an invasive species increasing the realized niche of native species, because in these cases the exotic species are only providing additional microhabitat, not changing any condition of the native species' fundamental niche.

Finally, various exotic plant species have a larger effect on nitrogen cycling in native ecosystems when the species are associated with symbiotic nitrogen-fixers (Ehrenfeld 2003). One of the most dramatic examples comes from the work of Vitousek et al. (1987) and Vitousek and Walker (1989) on the invasion of Morella faya in Hawaii. Morella faya is a nitrogen-fixing invasive plant that increases the $\mathrm{N}$ input into volcanic soils that are $\mathrm{N}$-poor. Changes in $\mathrm{N}$ availability favor the subsequent establishment of native plants that are able to establish only in relatively fertile soils, and otherwise unable to establish in volcanic areas. These increases in local distribution and number of individuals occurred without any reported effect on their tolerance to abiotic conditions (i.e., tolerance to soil with low levels of $\mathrm{N}$ ). Therefore, these change only have an effect on the spatial distribution or abundances, and thus changing the realized niche of the native species without affecting any of the conditions that characterize their fundamental niches (Kearney 2006, Pullian 2000).

\section{Discussion}

These examples show that interactions with exotic facilitators can increase the size of the realized niche by increasing the spatial distribution (reducing dispersal limitations), or by modifying the physical and chemical conditions of the habitats. However, whether the new range of conditions experienced by the recipient species is greater than that predicted by the fundamental niche is uncertain because, in most cases, we do not even know what is the fundamental niche. Facilitation may lead to an increase in size of the realized niche beyond that of the fundamental niche only if niche evolution occurs. However, niche evolution would only be possible if facilitative interactions were to create novel opportunities, such as those observed in several symbiotic associations. For example, the association between several vascular plants and fungi [i.e., mycorrhiza, (Wilkinson 2001)] and bacteria [i.e., Rhizobia, (Denison 2000)] has clearly contributed to the expansion of their geographic distribution over the fundamental niches of both species. Similar examples in which the fundamental niche of a species has increased as a result of facilitation are the interaction between algae and fungi in lichens, and the interaction between coral and zooxanthellae. Only in such cases, where neither of the species could persist in a new area without the other species, is the realized niche occupied by the mutually obligate species greater than the fundamental niche occupied by each species in isolation from the other.

We consider that, since Hutchison (1957) emphasized the role of interspecific competition when describing the realized niche, negative interactions became the core of niche theory for over 50 years. A clear example is Austin (1999), who described the fundamental niche of a species as its distribution in the absence of inter- 
specific competition, and the realized niche as the species' distribution following competition and other biotic interactions. Consequently, if the fundamental niche were defined only as the physical requirements of the species, the realized niche of the species would be greater than its fundamental niche in the presence of only positive interactions [Bruno et al. (2003) paradox]. However, Hutchinson's definition of the fundamental niche included all physical and biological requirements for the species to persist (Hutchinson 1957; p. 416). Here, we are not suggesting that the inclusion of facilitation to niche theory as proposed by Bruno et al. (2003) is incorrect. The accomplishment of Bruno et al. (2003) in incorporating positive interactions into ecological theory is outstanding and beyond debate. What we are suggesting is that facilitation can, and certainly does, contribute to the mitigation of negative interactions, but facilitation cannot cause the expansion of the realized niche over the fundamental niche. We nevertheless show that positive interactions may allow a greater filling of the fundamental niche of a species. Thus the inclusion of facilitation into niche theory may be better characterized as the processes, both physical and/or biological, that can expand the n-dimensional hypervolume of the realized niche that meets the requirements of the fundamental niche, and can alleviate the effects of negative interactions and abiotic stress.

\section{Acknowledgments}

We wish to thank J. P. Lessard for all his help on developing the ideas for this manuscript, and Q. Read, N.J. Sanders, D. Simberloff, J.J. Stachowicz, K.L. Stuble, D.P. Vázquez and R.J. Warren II for providing comments and suggestions that greatly improved previous versions of the manuscript.

\section{Referees}

John J. Stachowicz - jjstachowicz@ucdavis.edu University of California Davis

Robert Warren, II - hexastylis@gmail.com Yale University

\section{References}

Aizen, M.A., Morales, C.L. and J.M. Morales. 2008. Invasive mutualists erode native pollination webs. PLoS Biol. 6:e31. CrossRef

Austin, M.P. 1999. A silent clash of paradigms: some inconsistencies in community ecology. Oikos 86: 170-178. CrossRef
Bronstein, J.L., Wilson, W.G. and W.E. Morris. 2003. Ecological dynamics of mutualist/antagonistic communities. American Naturalist 162:24-39. CrossRef

Brooker, R.W., Maestre, F.T., Callaway, R.M., Lortie, C.L., Cavieres, L.A., Kunstler, G., et. al. 2008. Facilitation in plant communities: the past, the present, and the future. Journal of Ecology 96:18-34.

Bruno, J.F., Stachowicz, J.J. and M.D. Bertness. 2003. Inclusion of facilitation into ecological theory. Trends in Ecology and Evolution 18:119-125. CrossRef

Callaway, R.M. 2007. Positive interactions and interdependence in plant communities. Springer, New York, USA.

Callaway, R.M., Brooker, R.W., Choler, P., Kikvidze, Z., Lortie, C.J., Michalet, R., et al. 2002. Positive interactions among alpine plants increase with stress. Nature 417:844-848. $\underline{\text { CrossRef }}$

Chase, J.M. and M.A. Leibold. 2003. Ecological Niches: Linking classical and contemporary approaches. The University of Chicago Press, Chicago and London.

Chase, J.M. and J.A. Myers. 2011. Disentangling the importance of ecological niches from stochastic processes across scales. Philosophical Transactions of the Royal Society B 366:2351-2363. CrossRef

Choler, P., Michalet, R. and R.M. Callaway. 2001. Facilitation and competition on gradients in alpine plant communities. Ecology 82:3295-3308. CrossRef

Denison, R.F. 2000. Legume sanctions and the evolution of symbiotic cooperation by rhizobia. American Naturalist 156:567-576. CrossRef

Ehrenfeld, J.G. 2003. Effects of exotic plant invasions on soil nutrient cycling processes. Ecosystems 6: 503-523. CrossRef

Elton, C. 1927. Animal Ecology. Sidgwick \& Jackson, London.

Gause, G.F. 1934. The struggle for existence. Williams and Wilkins, Baltimore. CrossRef

Grinnell, J. 1917. The niche-relationships of the California thrasher. The Auk 34:427-433. CrossRef

Hardin, G. 1960. The competitive exclusion principle. Science 131:1292-1298. CrossRef

Hubbell, S.P. 2001. The Unified Neutral Theory of Biodiversity and Biogeography. Princeton University Press, Princeton, USA.

Hutchinson, G.E. 1957. Concluding remarks. population studies: animal ecology and demography. Cold Spring Harbor Symposia on Quantitative Biology 22:415-427. CrossRef

Janzen, D.H. 1970. Herbivores and number of tree species in tropical forests. American Naturalist 104:501528. $\underline{\text { CrossRef }}$ 
Kearney, M. 2006. Habitat, environment and niche: what are we modeling? Oikos 115:186-191. CrossRef

Kylafis, G. and M. Loreau. 2011. Niche construction in the light of niche theory. Ecology Letters 14:82-90. CrossRef

Leibold, M.A. 1995. The niche concept revisited: mechanistic models and community context. Ecology 76: 1371-1382. CrossRef

Levine, J.M. and J. HilleRisLambers. 2009. The importance of niches for the maintenance of species diversity. Nature 461:254-257. CrossRef

MacArthur, R.H. 1958. Population ecology of some warblers of northeastern coniferous forests. Ecology 39:599-619. CrossRef

Marino, P.C., Eisenberg, R.M. and H.V. Cornell. 1997. Influence of sunlight and soil nutrients on clonal growth and sexual reproduction of the understory herb Sanguinaria canadensis L. Journal of the Torrey Botanical Society 124:219-227. CrossRef

Ness, J.H. 2004. Forest edges and fire ants alter the seed shadow of an ant-dispersed plant. Oecologia 138:448-454. CrossRef

Paine, R.T. 1966. Food web complexity and species diversity. American Naturalist 100:65-75. CrossRef

Pearson, D.E. 2009. Invasive plant architecture alters trophic interactions by changing predator abundance and behavior. Oecologia 159:549-558. CrossRef

Pearson, D.E. and R.M. Callaway. 2003. Indirect effects of host-specific biological control agents. Trends in Ecology and Evolution 18:456-461. CrossRef

Pulliam, H.R. 2000. On the relationship between niche and distribution. Ecology Letters 3:349-361. CrossRef

Richardson, D.M., Allsopp, N., D’Antonio, C.M., Milton, S.J. and M. Rejmánek. 2000. Plant invasion - the role of mutualisms. Biological Reviews 75: 63-93. CrossRef

Riera, N., Traveset, A. and O. García. 2002. Breakage of mutualisms by exotic species: the case of Cneorum triccon L. in the Balearic Islands (Western Mediterranean Sea). Journal of Biogeography 29: 713-719. CrossRef

Rodriguez, L.F. 2006. Can invasive species facilitate native species? Evidence of how, when, and why these impacts occur. Biological Invasions 8:927939. CrossRef

Schwindt, E. and O.O. Iribarne. 2000. Settlement sites, survival and effects on benthos of an introduced reef-building polychaete in a SW Atlantic coastal lagoon. Bulletin of Marine Science 67:73-82.

Stachowicz, J.J. 2001. Mutualism, facilitation, and the structure of ecological communities. BioScience 51:235-246. CrossRef
Tilman, D. 1994. Competition and biodiversity in spatially structured habitats. Ecology 75:2-16. CrossRef

Valiente-Banuet, A., Rumebe, A.V., Verdu, M. and R.M. Callaway. 2006. Modern quaternary plant lineages promote diversity through facilitation of ancient tertiary lineages. Proceedings of the National Academy of Sciences of the United States of America 103:16812-16817. CrossRef

Van der Putten, W.H. 2009. A multitrophic perspective on functioning and evolution of facilitation in plant communities. Journal of Ecology 97:1131-1138. CrossRef

Vergnon, R., Dulvy, N.K. and R.P. Freckleton. 2009. Niche versus neutrality: uncovering the drivers of diversity in a species-rich community. Ecology Letters 12:1079-1090. CrossRef

Vitousek, P.M. and L.R. Walker. 1989. Biological invasion by Myrica faya in Hawaiúi: plant demography, nitrogen fixation, ecosystem effects. Ecological Monographs 59:247-265. CrossRef

Vitousek, P.M., Walker, L.R., Whiteaker, L.D., Mueller-Dombois, D. and P.A. Matson. 1987. Biological invasion by Myrica faya alters ecosystem development in Hawaii. Science 238:802-804. CrossRef

Warren II, R.J., Giladi, I. and M.A. Bradford. 2010. Ant-mediated seed dispersal does not facilitate niche expansion. Journal of Ecology 98:1178-1185. CrossRef

Wilkinson, D.M. 2001. Mycorrhizal evolution. Trends in Ecology \& Evolution 16:64-65. CrossRef

Wonham, M.J., O'Connor, M. and C.D.G. Harley. 2005. Positive effects of a dominant invader on introduced and native mudflat species. Marine EcologyProgress Series 289:109-116. CrossRef

\section{Response to referee}

Defining the niche is a current challenge for ecology, given the importance of the concept (Vazquez 2005). We agree with Stachowicz (2012) that species interactions can both shrink or expand the realized niche, and also that positive interactions allow species to occur in areas from which they would otherwise be restricted. However, we disagree that geographical expansion of the distribution of one species due to facilitation does imply that the realize niche is larger than the fundamental. Stachowicz (2012) stated that the reason for this disagreement is whether the conceptualization of the fundamental niche is based on an abstract sense or as a physical location. However, Hutchinson's definetion of the fundamental niche included all physical and biological requirements for the species to persist (Hutchinson 1957, p. 416). Consequently, if the physical 
and biological requirements of the species have not changed, neither has its fundamental niche.

We agree with Stachowicz (2012) that in symbiotic interactions - in which neither of the species could persist in a new area without the other species-the realized niche occupied by the mutually obligate species is greater than the fundamental niche occupied by each species in isolation. In our paper we discussed several examples of this, including the association between several vascular plants and fungi (i.e., mycorrhiza) or bacteria (i.e., Rhizobia), the interaction of algae and fungi in lichens, and the interaction between coral and zooxanthellae. Additionally, we identified the novel ndimensional hypervolume of the symbiotic interaction as "niche evolution", but these are special cases of positive interactions.

In conclusion, the inclusion of positive interaction into niche theory may be better characterized as the processes, both physical and biological, that can mitigate the impacts of abiotic stress and biotic interactions and can expand the realized niche inside the limits of the fundamental niche. Perhaps the only exception is the special cases of symbiotic association, which can promote niche evolution. Finally, we agree with Stachowicz (2012) that we need more studies focused on niche-expanding effects of positive interactions that shed light on this controversy.

Bruno, J.F., Stachowicz, J.J. and M.D. Bertness. 2003. Inclusion of facilitation into ecological theory. Trends in Ecology and Evolution 18:119-125. CrossRef

Hutchinson, G.E. 1957. Concluding remarks. population studies: animal ecology and demography. Cold Spring Harbor Symposia on Quantitative Biology 22:415-427. CrossRef

Stachowicz, J.J. 2012. Niche expansion by positive interactions: realizing the fundamentals. A comment on Rodriguez-Cabal et al. Ideas in Ecology and Evolution 5:42-43. CrossRef

Vazquez, D.P. 2005. Reconsidering the Hutchinsonian niche. Ecologia Austral 15:149-158. 